Transgovernmental networks in the European Union Improving compliance effectively?

Hobolth, Mogens; Martinsen, Dorte Sindbjerg

Published in:

Journal of European Public Policy

DOI:

10.1080/13501763.2013.800791

Publication date:

2013

Document version

Early version, also known as pre-print

Citation for published version (APA):

Hobolth, M., \& Martinsen, D. S. (2013). Transgovernmental networks in the European Union: Improving compliance effectively? Journal of European Public Policy, 20(10), 1406-1424.

https://doi.org/10.1080/13501763.2013.800791 


\title{
Transgovernmental networks in the European Union: Improving compliance effectively?
}

\author{
Mogens Hobolth and Dorte Sindbjerg Martinsen \\ Journal of European Public Policy (2013), Vol. 20:10, pp. 1406-1424 \\ http://www.tandfonline.com/doi/abs/10.1080/13501763.2013.800791\#.VIhIWrd0y70
}

\begin{abstract}
The application of European Union (EU) rules is, in general, the responsibility of national executives. This key intergovernmental aspect of the EU's administrative order makes compliance with supranational law vulnerable to distortion. However, the European executive has added important fire-alarm oversight mechanisms by means of transgovernmental networks (TGNs) to its toolbox. This paper examines the work-mode, horizontalness and effectiveness of such networks as newer governance tools to oversee and monitor the compliance with EU law. It draws on a unique dataset on the Solvit network, enabling us to examine effectiveness and variation of a transgovernmental network in operation. The paper substantiates the relevance of TGNs in identifying and solving manifold and complex problems of misapplied EU law, finds that the Commission constitutes a focal point in this type of multilevel executive and points out that learning in part explains why effectiveness varies across member states.
\end{abstract}

Key words: compliance, effectiveness, internal market, multilevel executive, transgovernmental networks 


\section{Introduction}

Domestic public administrations are the main actors responsible for implementing EU legislation (Versluis 2007). Applications for family unification under EU-law are processed by national immigration authorities. Recognition of foreign professional qualifications is granted by member states organisations. And so forth. This fundamental intergovernmental feature of the European Union's administrative order makes the shared rules "vulnerable to distortion" (Egeberg 2008: 247). Indeed, existing research has found that national compliance with EU obligations differs considerably and that implementation problems abound (see for example Falkner et. al. 2007; Haverland and Romeijn 2007; Börzel et. al. 2010).

Scholarly work aimed at understanding member state compliance has probed the importance, characteristics and effectiveness of different institutional oversight mechanisms put in place at the national and supranational level to improve compliance within EU law (Tallberg 2002; Jensen 2007). The analytical focus has been on infringement proceedings initiated by the European Commission as a centralized enforcement mechanism, and litigation through national courts interacting with the European Court of Justice as a more de-central avenue. Emphasis in the literature has thus been on the formal, legal channels for redress.

Yet it is also increasingly recognized that other institutional innovations play a role in monitoring and advancing compliance (Hartlapp 2007; Börzel et al. 2010). The executive order in Europe has been gradually transformed as a new 'European administrative space' has taken shape (Egeberg 2008; Trondal 2009). As part of this development, European regulatory networks have been found to have a major impact on domestic legislation and practices (Yesilkagit 2011; Thatcher and Coen 
2008; Maggetti and Gilardi 2011). National experts exchange best practices, negotiate guidelines and monitor the performance of each other in networks.

Regulatory or 'transgovernmental' - as conceptualized in this paper - have proliferated and "their extent and the issue areas covered have reached completely new dimensions in the international sphere" (Thurner and Binder 2009: 83). However, our understanding of the modus operandi and effects of such networks remains rather vague and findings on their potential impact are so far somewhat "inconclusive" or lack empirical substantiation (Yesilkagit 2011: 962, 966; Maggetti and Gilardi 2011: 830).

This article aims to contribute to our understanding of key features of EU transgovernmental networks, their work mode and effectiveness. We do so through an analysis of a network, operating in close interaction with citizens and businesses, using a 'fire-alarm' oversight mechanism (McCubbins and Schwartz 1984). The case studied is the European Union's Solvit network which allows nationals and corporations to lodge complaints over the domestic application of EU internal market law. These are then sought addressed through informal dialogue between involved public administrations (COM 2011a). ${ }^{\mathrm{i}}$ The network merits attention for a set of reasons. Firstly, whereas existing research has tended to focus on formal legal transposition, the disputes dealt with in this type of network concerns administrative decisions in concrete instances. Studying Solvit thus contributes to taking compliance research beyond transposition into the 'black box' of practical application of EU law (Versluis 2007). Secondly, the network has started to process a quite high amount of disputes. In 2010, it handled approximately 1.400 requests paralleling the case-load in the formal infringement procedure (see section 4 below). Thirdly, analysing Solvit furthers our overall understanding of the emerging EU multilevel executive, where the daily practices of 
monitoring and overseeing compliance of EU law has moved the European administrative order beyond its classic intergovernmental set up.

Drawing on existing research into network dynamics, oversight mechanisms and the wider literature on compliance we set up a theoretical framework for studying central characteristics of such transgovernmental networks, and understanding preconditions for their effectiveness. The model highlights, in particular, the overall importance of modes of relations and learning. Learning is here understood broadly as the built-up of knowledge on EU law, developing problem-solving knowhow and establishing working relations with other actors.

This theoretical setup is then deployed in the study of Solvit. We collected data on the network through a comprehensive cross-national survey covering all the Solvit centres, i.e. the centres in each EU member state plus Norway, Liechtenstein and Iceland, the three states from the European Economic Area (EEA). Furthermore, the responsible Solvit unit within the European Commission provided us data on the resolution rates of all Solvit cases all years from 2003-2011. Below we thus present and analyse a unique dataset, enabling us to examine effectiveness and key elements of a transgovernmental network in operation.

The paper is structured as follows. The next section locates our study in the existing literature, and sets out our theoretical conceptualisation of network based fire-alarm oversight. Section three presents the data and methods utilized. Part four presents the Solvit network. Part 5 and 6 contain the empirical analysis. Part 5 examines the work-mode of the network as well as the role of the Commission within it. Part 6 analyses the network's effectiveness and why it varies. Finally, section 7 concludes on the theoretical and empirical findings. 


\section{Compliance, fire-alarms and transgovernmental networks}

This section sets out our theoretical conceptualisation of transgovernmental networks as instruments of monitoring the application of EU law. We draw on the literature on compliance (Chayes and Chayes 1993; Falkner et. al. 2007), research on oversight mechanisms (McCubbins and Schwartz 1984; Jensen 2007; Tallberg 2002) and analysis of network dynamics (Maggetti and Gilardi 2011; Yesilkagit 2011). The model we present integrates a 'demand-side' understanding of compliance and oversight with an emphasis on the importance of network interaction and learning as preconditions for successfully addressing misapplication. Specifically, we pinpoint key characteristics of such institutional structures and argue that the effectiveness of network-based firealarm monitoring mechanisms is likely to increase as the demand for the application of supranational rules rises, since rising number of cases generate learning improving the capacity to resolve cases. In turn, this might feedback and spur even further growth in number of cases.

In general, compliance research is concerned with the extent to which, and why, adopted rules are followed by the relevant addressees. Here we focus on rule-adherence in relation to the practical application of EU law and not prior formal-legal transposition acts (cf. Versluis 2007: 51). Citizens and businesses encounter complex problems of practical application of EU law when they attempt to trade, move and work across borders within the European single market. For the internal market to work, a myriad of public actors at local, regional and state levels must understand and act in accordance with EU goals. The figure below present two examples, drawn from the 2010 annual Solvit report (Com 2011a, annual report 2010: 28, 31), illustrating some of the manifold problems that can and do arise: 


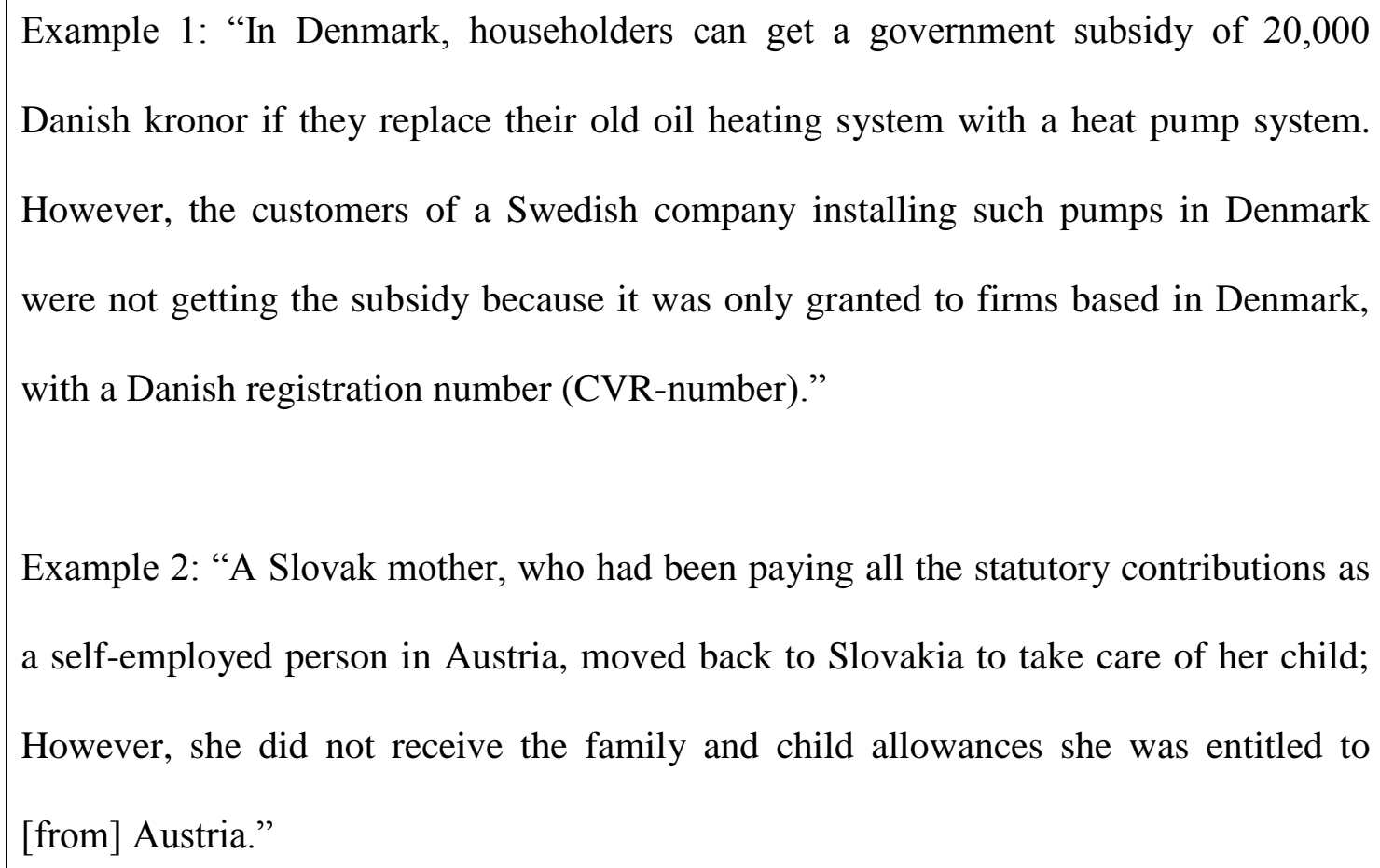

Example 2: "A Slovak mother, who had been paying all the statutory contributions as a self-employed person in Austria, moved back to Slovakia to take care of her child; However, she did not receive the family and child allowances she was entitled to [from] Austria."

In the first example we see how the detailed domestic regulation of a subsidy program results in discriminatory implementation practices. The requirement for companies to have a Danish registration number gives Danish firms an advantage. The internal market, as the second example shows, is also about free movement for EU-citizens and the social infrastructure needed to ensure that they can work and conduct business across borders. Here practical problems in claiming child and family allowances earned abroad creates an obstacle to mobility.

The two cases suggest that the dynamics giving rise to misapplications are complex and likely to be difficult to disentangle. In both instances it might very well be that standard administrative procedures and practices are simply not yet well-adapted to the single market. In the Danish case, a CVR number might be 'the usual way' to coordinate and manage different subsidy programs. For Austrian authorities, paying family and child allowance for non-residents could be 'a rare event'. If so, perhaps no established structures are in place for handling international bank accounts and a 
non-residency status of a claimant. Yet it could also be the case that misapplication is informed by more overt government strategies to sidestep the constraints and obligations arising from the internal market program. Austria might not be interested in paying child and family allowances to a Slovak citizen no longer resident and this could give rise to administrative delays and obstruction tactics. Similarly, the Danish subsidy program might be in place partly to support domestic businesses. The detailed rules and regulations will thus be designed intentionally to prioritise national firms.

Facing such entangled problems of 'management' (adapting administrative procedures, increasing knowledge) and 'enforcement' (explicit government obstruction, delaying tactics) (Chayes and Chayes 1993) two key challenges stand out. Firstly, the problems must be identified. Secondly, once brought to attention they must be rectified.

In terms of identifying and monitoring misapplication, the literature distinguishes between so-called 'police patrol' and 'fire-alarm' mechanisms (McCubbins and Schwartz 1984; Tallberg 2002; Jensen 2007). Police patrol entails direct surveillance of the implementing agency. For example, the European Commission might request annual or biannual reports detailing the measures adopted and the guidelines pursued. It could also arrange for agency directors to routinely participate in meetings and explain the practices pursued. Yet if direct surveillance is to succeed it is likely to be highly expensive. Take the examples above. Even if the national authorities did explain to the Commission how the subsidy and allowance programs were implemented, it would require considerable resources and in-depth knowledge to identify and correctly predict how minute government regulations might bias the internal market. Given the scarcity of resources, control is 
bound to be targeted. Yet knowing where to concentrate attention would in itself require substantial information about implementation practices and interests on the ground.

Fire-alarm oversight, in contrast, relies on citizens, interest groups and businesses for bringing light to compliance problems. Instead of mandating government agencies to report on their practices, channels should be in place for private actors to report when rules are misapplied. As part of the infringement procedure, for example, citizens and businesses can complain to the Commission about application problems. From the perspective of oversight authorities, a fire-alarm has the advantage of shifting costs to private actors. It could also overall be a more efficient mode of monitoring. Striking a critical note, Jensen (2007) argues that fire-alarm models might not be particularly appropriate in the context of much EU-regulation as domestic actors could be in favour of government agencies side-stepping obligations under EU law. Domestic firms profiting from lax implementation of EU chemical safety standards will not sound the alarm; nor will construction firms complain about being spared costly checks of workplace safety rules. This criticism helps us to tease out key logics and assumptions of the fire alarm model, operating in a multi-level setting.

Firstly, the model is based on a pluralistic understanding of state and society. The actions of chemical firms are followed by environmental groups which will seek to bring to light problematic practices. Unions monitor health and safety standards and will complain when firms do not comply. Citizens will not respond passively to adverse decisions but will actively search for means of redress. Still, pluralism can be criticised for ignoring or overlooking differences in influence and ability to organize. Businesses, for example, might often be at an advantage in policy-making processes. Yet if fire-alarms mechanisms are widespread and easy to access such inequalities can at least partly be taken into account. Allowing for redress through several channels such as domestic 
courts, the Commission and informal means like Solvit enables several actors of diverse standing to lodge complaints. Furthermore, cross-border interactions enlarge the field. Although national construction firms will not complain over the CVR number requirement, Swedish firms detecting a potential market opening will. Austrian citizens residing at home will not protest over ways in which child allowance payments are geared towards the domestic scene, but other EU-citizens will.

Secondly, the fire-alarm model is based on a somewhat different understanding of compliance than is otherwise often found in the EU implementation literature. By comparing transposition delays and infringement proceedings across member states researchers conclude, for example, that some member states are less compliant than others because implementation is more often delayed or more infringement cases are opened by the Commission (see for example Börzel et. al. 2010; Haverland and Romeijn 2007). The fire alarm approach takes a somewhat different 'demand-side' approach to compliance. From this perspective, a policy such as the internal market is likely to generate a myriad of problems in implementation and it would be impossible to predict and prevent them all in advance as they are revealed by practice. Instead, what is important is that the administrative practices can be brought into line when citizens and businesses find it expedient to use the internal market. Thus, a member state which is being complained about more than others need not be a bad complier. It could also simply mean that it is becoming a more attractive market or destination for internal EU migration, increasing the demand on public authorities to apply internal market rules. This result in more cases and complaints about implementation practices.

Let us turn then from detection of compliance problems to mechanisms for addressing them. Firealarm models tend to be linked with formal powers vested in courts or parliaments. In the context of transgovernmental networks the picture is different. Networks are characterised by relations that are 
neither coercive nor market-based. The resources mobilised are instead argumentation, reputation, mutual understanding and relevant knowledge. Transgovernmental networks can be defined as "a pattern of regular and purposive relations among like government units working across the borders that divide countries from one another and that demarcate the 'domestic' from the 'international' sphere" (Slaughter 2004: 14). They are usually composed of sector-specific experts who continuously interact, exchange views and problems, persuade, adapt, learn and develop shared standard operating practices (Slaughter Ibid.: 59; Trondal 2010: 22). Networks are thus management instruments of capacity building without any strong element of coercive control and punishment. They are generally horizontal and characterized by fairly independent interaction between the members (Slaughter and Hale 2010: 358). Two key overall elements of transgovernmental networks are thus the development of shared understandings and the establishment of working relations.

These key network traits point to the importance of learning, understood as "an improved understanding of causal relationships in the light of experience" (Meseguer 2005: 71), for successfully addressing misapplication. It takes time and practice to build up knowledge on EU law, know-how on problem-solving and develop relations and a reputation as a reliable and resourceful partner. This in turn suggests that the more cases processed the more institutional know-how is created resulting in more effective case resolution. Our analytical model of dispute settlement networks is thus as follows: 


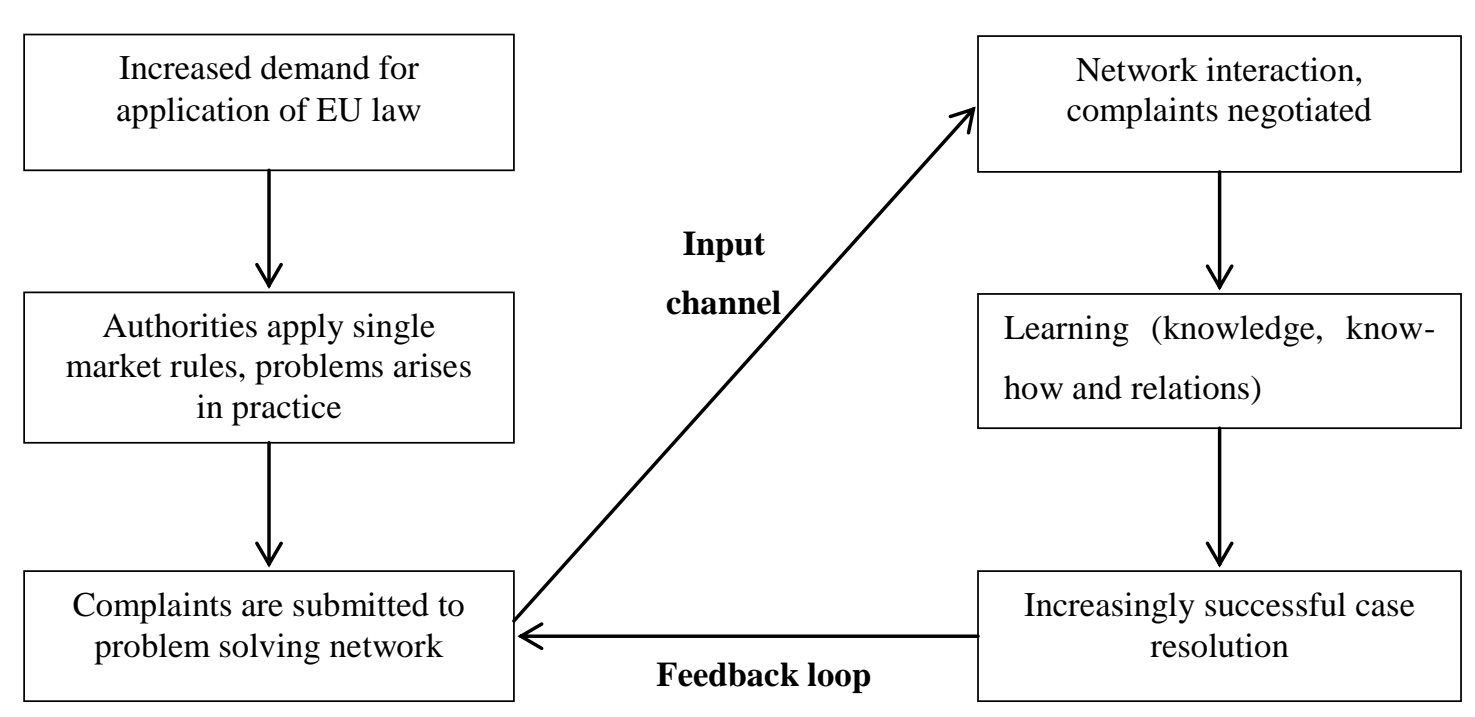

The left side of the model depicts the demand-driven process by which single market rules are increasingly sought used, applied and complained over. As cases are generated and submitted to the network, these provide the input for network interaction to start to occur. Through this interaction participants gradually learn, that is they acquire better understanding of EU law, practical skills for problem solving and develop good working relations with key partners.

Improved case resolution, in turn, has feedback effects. It can lead to more awareness of the network among citizens and businesses. As success builds up the network may attract more attention in the wider administrative system, and be able to secure more resources for outreach activities. The number of cases brought into the network thereby increases leading to additional interaction, learning, and so on. In the empirical analysis we focus on the right-side of this model interaction, learning and effectiveness - and do not explore further why and how cases are generated. 
Substantively addressing misapplication requires an understanding of and commitment to EU law. Participants must be able to agree on a range of correct and incorrect interpretations of European rules. This suggests that either the presence of an authoritative source of interpretation of law or the development of 'peer-review' processes for good practices is important. For example, the Commission could play a central role in a network as an informal but mutually recognized provider of valid interpretations of European legislation.

Solvit is a good case of such a transgovernmental network-based fire alarm. It offers citizens and businesses a free and easily accessible channel for lodging complaints. The network is thus highly open and consequently sensitive to what is happening on the ground. With its informal soft powers it is not designed to address 'high-politics' cases of overt resistance and national opposition. Instead, it aims to provide fast and pragmatic solutions to the many compliance problems that arise in a complex field characterised by elements of lack of knowledge, engrained administrative practices, and some elements of domestic reluctance to adaptation. Having thus set out our overall theoretical conceptualisation of transgovernmental network-based fire alarm, we now move to present and analyse the empirical data on the case.

\section{Data and method}

The empirical basis of this article consist of two original data sets; 1) data collected by means of an on-line survey inquiring into the relations, work methods and values of the Solvit network (Couper 2000) and 2) data provided by the European Commission on the resolution rates of the individual Solvit centres, extracted from the Commission's database. The web questionnaire was sent out at the beginning of 2011 and we secured responses from all Solvit members. ${ }^{\text {ii }}$ The data from the Commission is not publicly available but was provided by the Commission on our request on the 
basis of previously established contact. We consider the datasets unique, allowing us to comprehensively study the modus operandi and effectiveness of the network. We use descriptive statistics to analyse the data.

The concepts at the centre of the analysis were operationalized as follows. Effectiveness ('case resolution' in the analytical model) was assessed using a set of different measures. We used, first and foremost, the Commission data on case resolution rates. This we supplement with survey questions on the precise outcome of Solvit interventions and Commission provided data on case

resolution times. ${ }^{\text {iii }}$ Learning processes was captured by the Commission data on the case load of the centres and resolution rates. Here we thus emphasise the aspect of learning relating to improved resolution rates through more practice. The relation to the Commission ('network interaction' in the model) was measured via the survey using a set of questions probing the level of contact with it and the role the Commission plays in the case management process.

\section{The Solvit network: addressing complex problems of misapplication}

The European Commission officially proposed the establishment of the Solvit network in late 2001, enabling citizens and enterprises to submit complaints to nationally-based centres if facing misapplication of internal market rules (COM 2001). In 2002, the network started to process cases. The case-load of the network has increased notably over the years (see figure 1 below). The network is demand driven and depends on cases of suspected misapplication being lodged by citizens or businesses. The latter makes the large majority of complaints. Although being an instrument of problem-solving within the internal market a large proportion of Solvit cases concerns social security. In 2010, complaints concerning social security made up $34 \%$ of the caseload, residence rights cases $23 \%$, whereas business cases were less prominent, being covered mainly 
under the areas of services and establishment (3\%), market access to products (4\%) and taxation (5\%) (DG Internal Market and Services 2011: 27).

The case-load of Solvit points to a significant demand to solve problems of internal market rules in practice. As figure 1 demonstrates the activity of the network stands out when compared to the traditional formal EU infringement procedure. In 2002 the network handled 70 cases, in 2003167 cases; by 2010 the figure had grown to 1363. In comparison the Commission sent on average about 1500 letters of formal notice from 2002 to 2009, issued 500 reasoned opinions and referred about 200 cases to court - notably across policy areas and not within a single one as the internal market (COM 2007, 2011b).

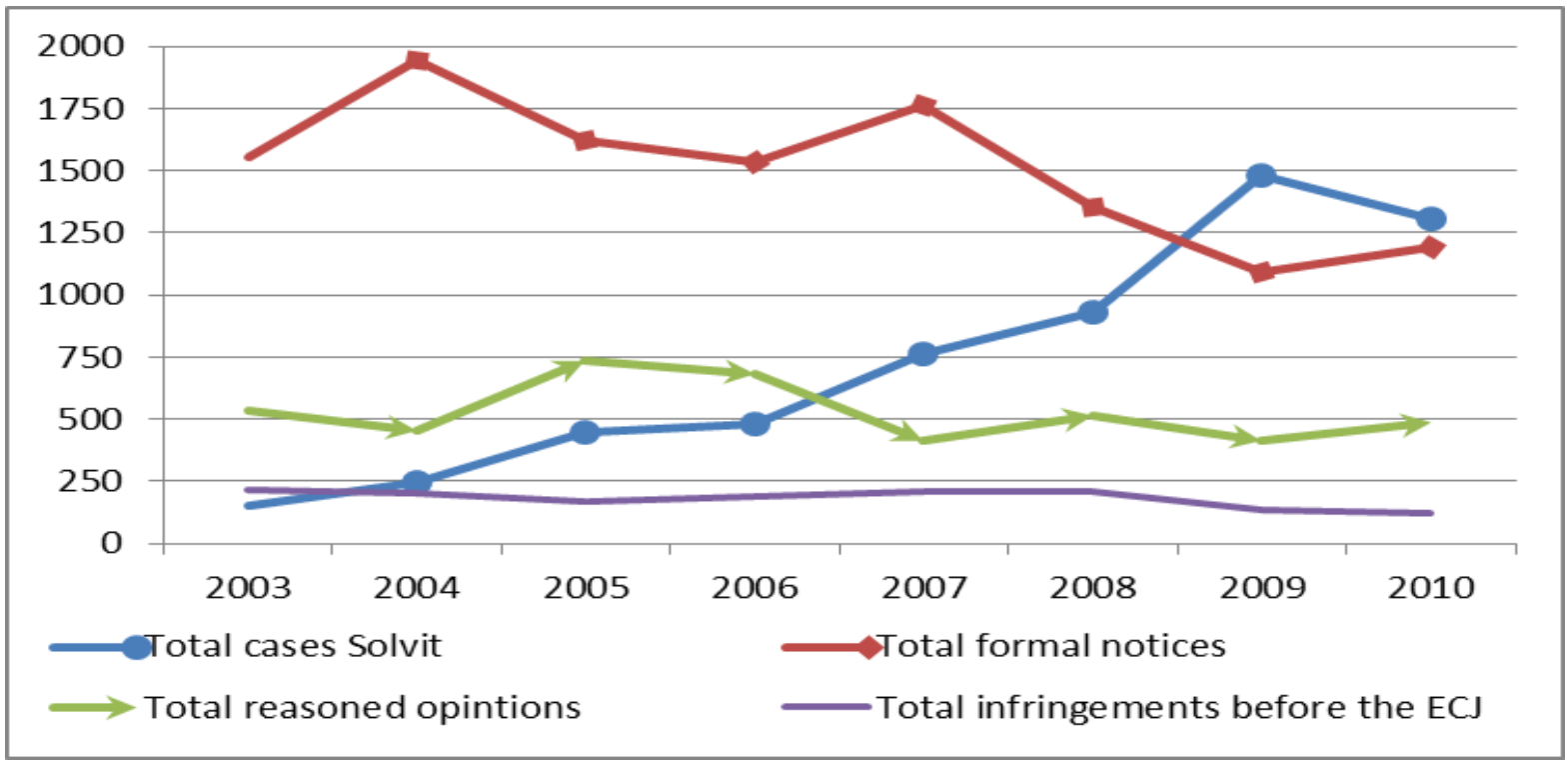

Figure 1: Solvit cases and infringement procedures compared 2002-2010. The data on infringement procedures are from the Commission's Secretariat General's annual reports on monitoring the application of Community law. The data on Solvit cases have been provided by the Commission. 
The increase in cases over time indicates that there is a demand and functional need for a transgovernmental network as Solvit. The network has, however, only been in operation in relatively few years and the figures should be interpreted with caution. Still, compared with the formal infringement procedure case numbers has been considerable. This highlights that alongside the focus on enforcement and infringements it is indeed necessary to address newer mode of governance, understand their work mode and executive function as well as how they may improve compliance.

\section{Work mode and horizontalness of a transgovernmental network}

Examining the work mode of the Solvit network allow us to capture the management logic of this newer mode of EU executive governance. As a transgovernmental network its problem-solving work-mode differs from the logic of enforcement. It is based on recurrent dialogues between citizens, companies, Solvit centres and responsible national authorities. A complaint on misapplication with internal market law is first lodged in a 'home' centre; the one in the home country of the applicant. If the home centre deems that the case is within the remit of internal market law and appears to involve a breach of it, the dispute is registered in the network and sent to the 'lead' centre. The 'lead' centre is located in the member state where the problem occurred. If it accepts the case, it subsequently initiates a dialogue with the national public authority complained about (COM 2001, 2011b).

The dispute settlement process involves several actors in a dialogue on the application of EU law. The citizen or company needs to present and give a reason to the 'home' Solvit centre, which again is to clarify, present and give reason on the dispute matter to the Solvit centre in the other member state, the 'lead' centre. The 'lead' Solvit centre then has to present the subject matter and breaches 
of EU law to the responsible national authority in its own member state. Last, the responsible national authority has to give reason and justify its methods, which again is reviewed and eventually criticized by the two Solvit centres. This exchange of arguments, our survey data evidences, is first and foremost carried out with reference to European law and how it should be applied (Solvit Survey 2011, questions 22, 27).

To what extent does a transgovernmental network operate autonomously without supranational supervision or intervention? The general literature on transgovernmental networks suggests that it should indeed be largely horizontal (Slaughter and Hale 2010). At first glance the Commission does not appear to play a central role in the Solvit network. It is not presented as a central actor in the dispute settlement process. Our survey, however, substantiates that the Commission in practice occupies a key position in the network.

Starting with the density of contact, most centres are in frequent contact with the Commission. When asked how often the national Solvit centre is in contact with the Commission, one centre responds "once or more a day", three centres "nearly every day", eight centres respond that they are in contact with the Commission on a "weekly" basis, twelve centres respond "a few times during the month" and the remaining six are in contact with the Commission "a few times during the year". iv Hence, although the level of contact varies, it is in general high. When asked whether the contact with the Commission has increased, decreased or remained constant over the years, "seventeen national centres reply that contact has "increased", two that it has "decreased" and nine that it has "remained constant". 
The Commission is contacted for three main purposes. ${ }^{\text {vi }}$ Firstly, the centres are in contact with the Commission with questions concerning the day-to-day use of the case management database. Secondly, the centres request clarification on the content and meaning of EU law. Thirdly, the Commission is asked to assist with solving horizontal disagreements, i.e. resolving disagreements with other Solvit centres. The Commission is not contacted, our Survey answer highlights, when it comes to disagreements between Solvit centres and national public authorities.

The centrality of the Commission is further substantiated by other answers to our survey. We asked the centres specifically to assess the role of the Commission in handling cases. ${ }^{\text {vii }}$ Eighteen centres either "agree" or "strongly agree" with the Commission being able to settle disputes between national Solvit centres, and twenty-four either "agree" or "strongly agree" with the Commission providing legal assessments clarifying the legal issues involved. Furthermore, when directly queried about how they would respond if the Commission were to recommend a case solution different from the one preferred by a national authority, 14 centres answer that they would follow the recommendation of the Commission and encourage the national agency to alter its decision through a new dialogue. No centre responds that they would uphold the solution advanced by the national agency. 16 centres did not answer or indicated that they had not been in the situation. ${ }^{\text {vii }}$

Thus, although presented as a horizontal network bringing together national administrative units, the Commission has an authoritative position when conflicts and ambiguities arise. In addition, it administers the database where cases and outcomes can be compared. Albeit horizontal and rather autonomous at first glance, the Commission is the mutual reference point for network participants, bringing supra-nationality in between the relations and contacts of national public authorities. The transgovernmental network has an important vertical component which is decisive when disputes 
are settled and participants orient themselves in accordance with Commission's advice and suggestions. The Commission appears to have a key role as an authoritative interpreter of European law, and its advice is requested and followed by the national counterparts of the multilevel executive.

\section{The effectiveness of a transgovernmental network}

Although the literature on transgovernmental networks generally presents them as effective governance instruments, the empirical proof of their effectiveness remain rather limited and unclear (Yesilkagit 2011; Maggetti and Gilardi 2011). Are these newer modes of executive governance, operating below the head of states, in informal manner and by means of management logics, actually able to solve complex problems when internal market rules are applied in practice? Are they relevant in practice? In this section the overall effectiveness of the Solvit network will be examined, the effectiveness of the Solvit units in the individual member states will be compared and a key explanation for variation on effectiveness will be presented.

Effectiveness is here operationalized by means of the ability of the network to solve a complaint submitted by a citizen or a business regarding the application of internal market rules. We thus classify a Solvit process as 'effective' when a case is registered as 'solved' in the Commission's database (COM 2011a). This overall definition of effectiveness contains two further qualifications; 1) effectiveness as time, i.e. the ability to solve a case within the deadline set by the Solvit network and 2) effectiveness as the ability to change national decisions. Time is an important dimension of effectiveness. Whether Solvit is able to perform within the deadline or not is important as to the extent to which Solvit performs speedy redress and thus represent an attractive alternative to formal problem solving mechanisms such as infringement procedures. Furthermore, a case registered as 
'solved' can in practice mean two different things: either a change of decision or a clarification. The former entails that the initial administrative act is altered following the intervention of Solvit, i.e. that misapplication is turned into correct application. The latter means that the claimant in the end only receives additional information clarifying the background and reasons behind the decision, but the decision is not changed since the conclusion is that EU law has been correctly applied by the national authority.

As figure 2 below demonstrates, the overall effectiveness of the Solvit network has improved over time. In $2003,76 \%$ of all cases were 'solved' whereas $86 \%$ of all Solvit cases were registered as 'solved' in 2011. Concerning effectiveness as time, speedy redress is an important performance indicator within the network itself. When a case is accepted by the home and the lead Solvit centres, the two centres have a deadline of 10 weeks to solve the case. 10 weeks must be seen as rapid dispute settlement, compared with formal infringement procedures or preliminary references before the European Court of Justice, running for years (Koops 2011: 9). If the Solvit centres cannot reach a solution within the deadline, they can be granted an extended deadline of 4 weeks, and if still not possible another 4 weeks can be granted to solve the case (COM 2011a: 20). From the complainants point of view 18 weeks must still be an attractive alternative to formal problem solving procedures where cases may easily run from 2-4 years (Koops ibid.). Figure 2 shows that in 2011, about 53\% of all Solvit cases were solved within the deadline of 10 weeks and $57 \%$ of the Solvit cases were solved within the extended deadline of 4 weeks. Adding a further 4 weeks to solve a case improve the resolution rate considerably as the upper line of general effectiveness shows. 


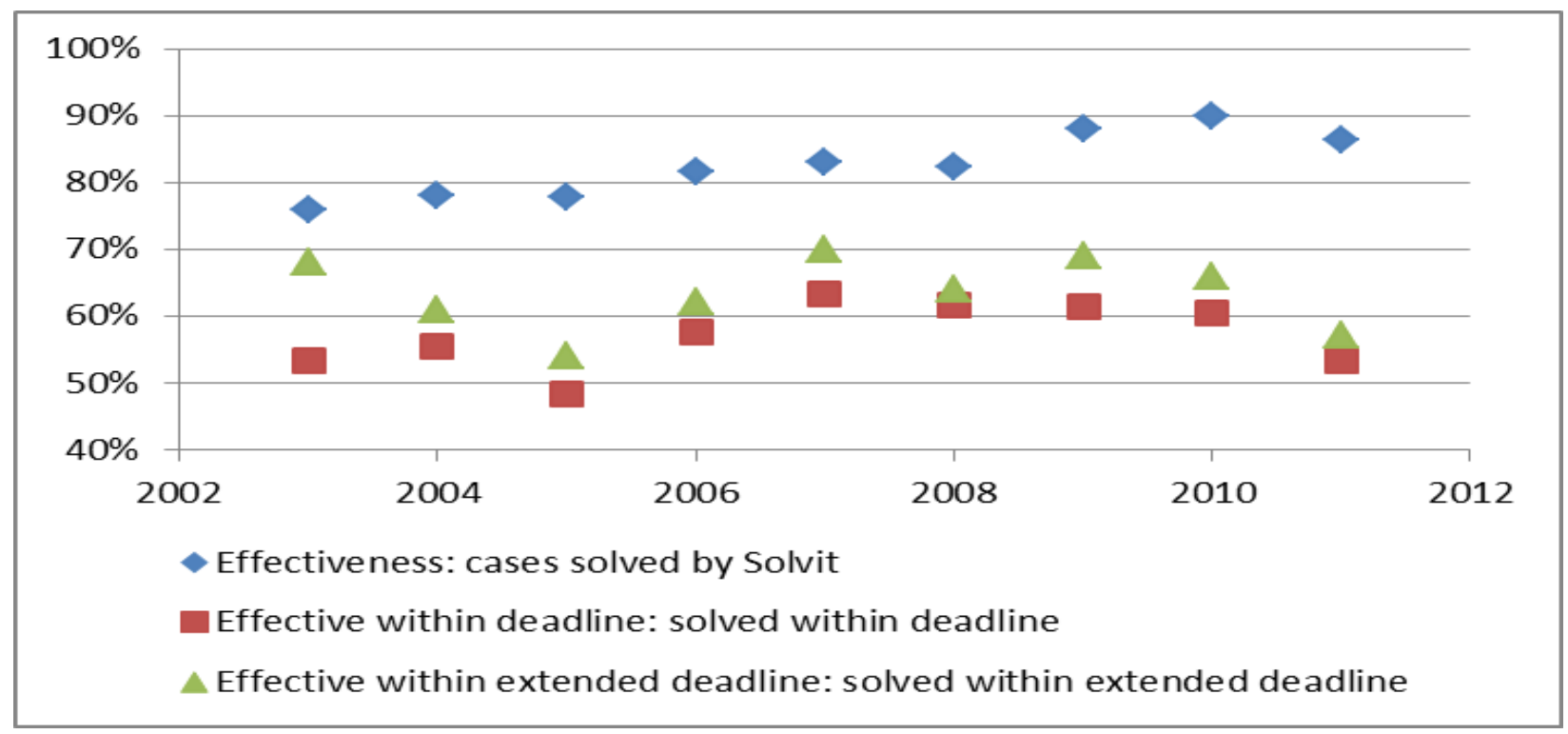

Figure 2: The effectiveness of the Solvit network 2003-2011; the resolution rates of Solvit within and beyond deadline. Data provided by the Commission, drawn from the Solvit database.

However, it could still be held that Solvit appears as effective because cases mainly end up with clarification, where the national authority is found to have applied EU law correctly. We thus need to look into how often decisions of national authorities are changed after the Solvit network has intervened in a case. The Commission states that $23 \%$ of all cases in 2010 ended with a clarification, implying that the rest of the cases actually led to a change of decision. In our survey we further probed this aspect. ${ }^{\text {ix }}$ One center reports that complaints ended with a change of decision in between $81-100 \%$ of the cases. Seven centers report that change of decision took place in between $61-80 \%$ of the cases. Eight centers found that change of decision happened in between 41 $60 \%$ of the cases. Nine indicate that changes are less common. Five centers answered 'do not know' or left the question blank. Although the centres might have an incentive to over-report on their impact, the network is able to affect compliance not solely by promoting dialogue and reasongiving in European legal terms. In the majority of member states Solvit is to a considerable degree able to turn misapplication of EU law into right application. These findings substantiate that the 
Solvit network acts with considerable effectiveness and with sufficient authority to change previous decisions of national authorities, thus correcting the application of EU law on the ground.

Furthermore, a recent evaluation of Solvit points out that the impact of the network on national compliance can be wider than the individual decision itself (DG Internal Market and Services 2011: 62). As part of the evaluation, government departments were asked whether Solvit cases which altered a previous national decision also resulted in changes of general administrative practices or changes to legislation. A third of the departments responded that $80 \%$ to $100 \%$ of the Solvit cases resulted in changes to administrative practices or legislation, in this way leading to long term solutions (DG Internal Market and Services 2011: 62, table 5.5). Thus the impact of the Solvit network goes beyond individual decision-making.

\section{Variation on effectiveness}

When the unit of analysis is disaggregated from the Solvit network as a whole into the individual EEA member states, represented by their Solvit centres it becomes clear that effectiveness varies between the countries. In this section, we use the overall definition of effectiveness where a Solvit process is classified as 'effective' when a case is registered as 'solved' in the Commission's database, disregarding whether a case lead to a 'change of decision' or a 'clarification' and disregarding whether it was solved within the deadline of 10 weeks.

Between 2003 and 2011, the EEA member states were on average able to solve 80,15\% of all Solvit cases. However, as figure 3 shows some member states perform considerably better than others. 


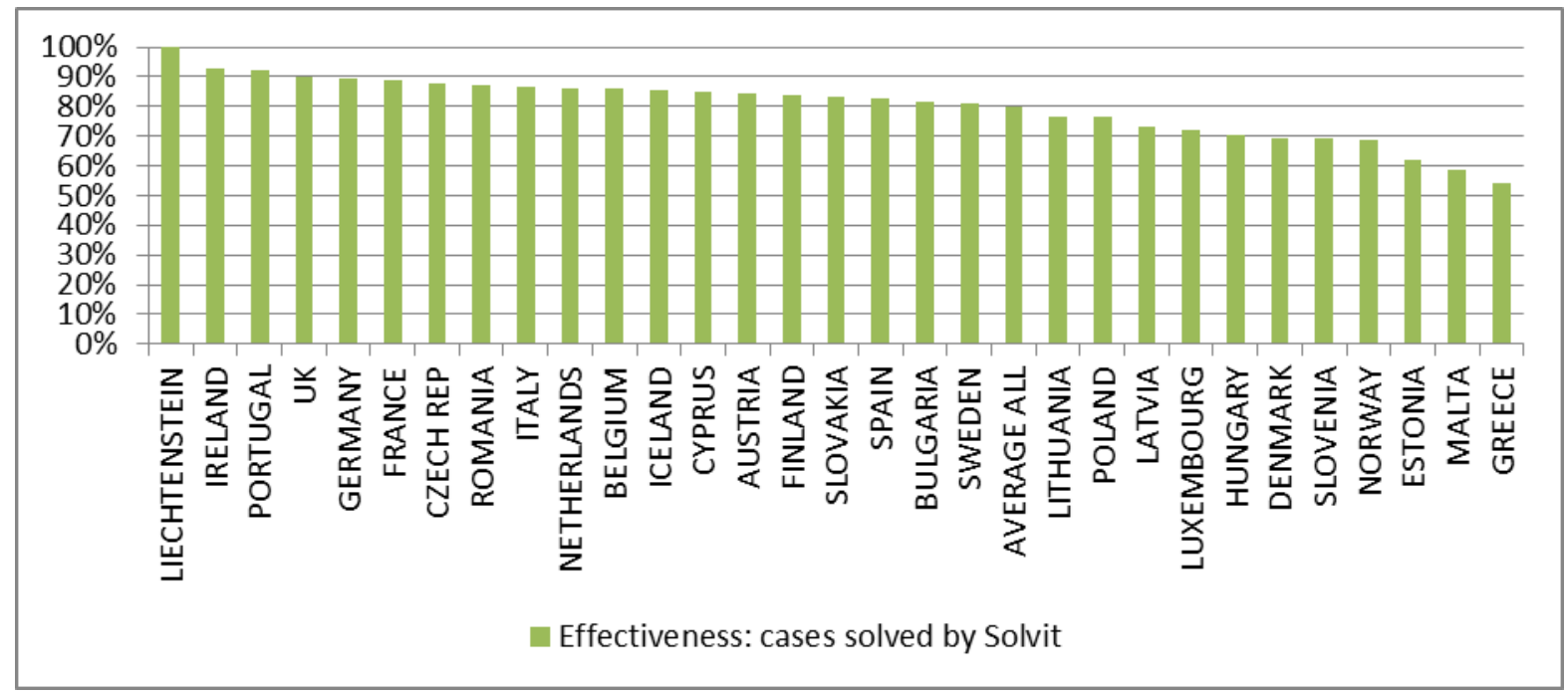

Figure 3: The effectiveness of individual Solvit member states 2003-2011. Data provided by the Commission, drawn from the Solvit database.

Lichtenstein is the best performer, having solved all its cases 2003-2011. Also belonging to the group of high performers, we have Ireland, Portugal, UK, Germany, France, the Czech Republic, Romania, Italy, the Netherlands, Belgium and Iceland, solving between $85 \%$ and $93 \%$ of all cases. At the other end of the scale, we have Latvia, Luxembourg, Hungary, Denmark, Slovenia, Norway, Estonia, Malta and Greece, solving between 73\% and 54\% of their cases between 2003 and 2011.

How can we explain this variation? A classic 'veto player' argument would make us assume that many veto players, would prevent high effectiveness, but among the best performers we find Portugal, Germany and Italy with institutional, federal and partisan veto players (see Maggetti and Gilardi 2011: 838 for the same finding). Effectiveness could also be argued to relate to the 'culture of compliance' of the different member states, being that 'law observant countries' will have higher ability to turn discovered misapplication into right application than countries, with tendencies to 'neglect' or which in practice ignore their European obligations (Falkner et. al. 2007). However, among the most efficient Solvit centers we find countries classified within the 'world of neglect', 
i.e. Ireland, Portugal, France and Italy and the 'world of dead letter', i.e. the Czech republic. At the other end of the scale, we find Denmark which belongs to the 'world of law observance' in the Falkner typology (Falkner et. al 2007). Thus 'cultures of compliance' does not explain why some Solvit centers are more efficient than others. What about administrative capacity? Perhaps conflict resolution ability is affected by the bureaucratic resources available for implementing EU rules (cf. Borzel et. al. 2010). The data does lend some support to this idea. Among the least effective centers we find states with relatively low administrative capacity such as Greece and Estonia (WB 2012). Among the high performers are mainly states with a high bureaucratic capacity. Several observations, however, do not seem in line with this hypothesis. Denmark and Norway have high administrative capacity but rank low in terms of effectiveness. The Czech center is quite effective despite relatively low bureaucratic resources. The main, established arguments in the compliance literature are thus not well-suited for understanding variation in the effectiveness of the centres.

Turning then to our theoretical model and emphasis on learning, how well does this argument stand up to empirical scrutiny? As seen in figure 4, case-load and effectiveness are positively correlated: ${ }^{\mathrm{x}}$ 


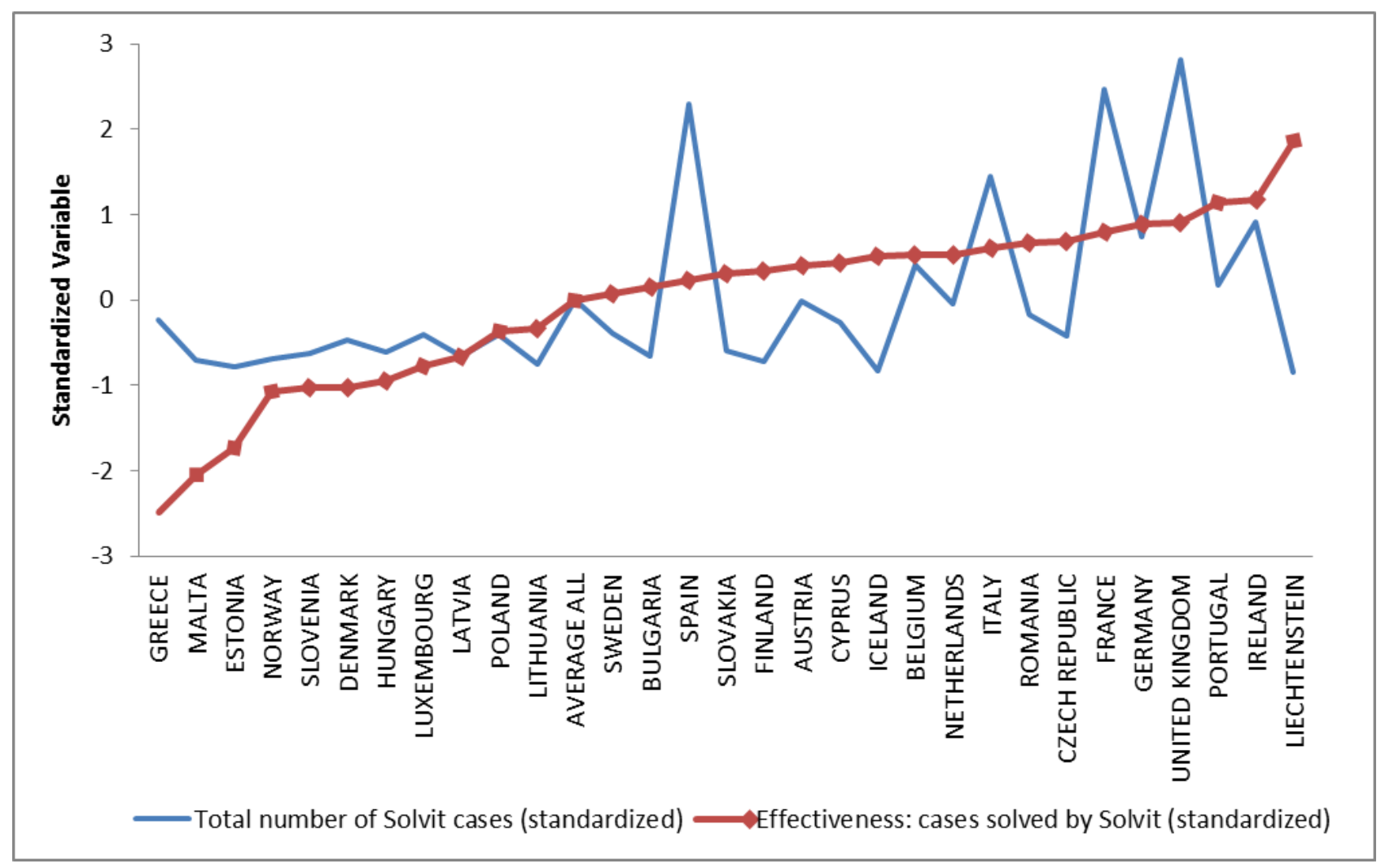

Figure 4: Learning effects. The relationship between case-load and effectiveness. Data provided by the Commission, drawn from the Solvit database.

The figure plots the member states from the least (Greece) to the most (Liechtenstein) effective. The red line shows their standardized effectiveness score and the blue line their standardized case load. The two follow each other quite closely. As the number of disputes processed increases so too does effectiveness. This trend supports the hypothesis that learning is important. Through the handling of still more cases knowledge, know-how and relations are built-up enabling the centres to resolve cases more effectively. They gain experience via increased interaction with other parts of the public administration and Solvit members improving their understanding of how cases can be solved informally. Not all states, however, perform as we would expect from this idea. Liechtenstein performs better than we would expect. Malta, Greece and Spain should be more effective relative to 
their case load. The same is the case for France and the United Kingdom. However, as their effectiveness level is already among the highest with average resolution rates of $88 \%$ and $90 \%$ respectively, these last two cases might suggest that there is an upper threshold to the learning effect. Above a certain level, additional cases cease to improve the effect of the network. An element to this could be that other limitations are encountered, for example low staffing levels within the centres. Still, all in all learning appears to play a significant role in accounting for the varying impact of the Solvit network.

\section{Conclusion}

Based on new survey data and Commission provided empirics, we have in this paper examined the work-mode, horizontalness and effectiveness of transgovernmental networks as newer governance tools to oversee and monitor the compliance with EU law. The paper has shown that TGNs can constitute important fire-alarm oversight mechanisms in the EU multilevel executive, through which complex problems of misapplied EU law can be addressed - and effectively solved. The findings are important for various reasons. First, they show that the administrative order of the European Union has innovated new instruments, which operate transgovernmentally, below the head of states and rely on management logics of informal problem-solving. Secondly, although not noticeable at first glance, the Commission constitutes the focal point of the network, instructing its modus-operandi, shadowing the process all way through, and being the steady partner of the national units. The position to coordinate, give advice, clarify and evaluate is a powerful one. The important role of the Commission substantiates the multilevel character of the emerging EU executive. It is neither intergovernmental in a classic sense, nor strictly supranational. Instead of the Commission enforcing EU law from the distances of Brussels, it monitors the right application of EU law through national authorities, which are financed and located in the member states but 
assigned with the responsibility to oversee that EU rights and obligations are correctly applied by its domestic counterparts. The EU executive is embedded within the national public administration and vice versa.

Thirdly, the findings substantiate the relevance of these networks as innovative tools of governance, proving that they identify problems of practical application in the internal market (increased caseload) and are also effectively able to solve these problems (high resolution rates). Fourthly and finally, the analysis identifies that effectiveness varies between member states. We do not find support for more classical institutional explanations for such variation, but instead find a significant link between case load and effectiveness. This brings learning into the focus as highlighted in our theoretical model. Learning initiates when problems of practical application are identified and complaints submitted to the network. These complaints (Solvit cases) function as input for network interaction, upon which knowledge of EU law, know how on problem solving and transgovernmental relations consolidate and expand. Cases enable network participants to learn and strengthen their problem solving capacity, thus becoming more effective. Learning dynamics, however, do not account for all variation in effectiveness and would seem likely to interact with other factors such as staffing levels and the wider bureaucratic capacity.

Word count: 7514

Biographical note: Dr. Mogens Hobolth holds a PhD in European Studies from the London School of Economics and Political Science. 
Dorte Sindbjerg Martinsen is Professor (MSO) at the Department of Political Science, University of Copenhagen.

Address for correspondence: Dorte Sindbjerg Martinsen, Department of Political Science, University of Copenhagen, Øster Farimagsgade 5, 1353 Copenhagen K, Denmark. E-mail: $\underline{\text { dm@ifs.ku.dk }}$

ACKNOWLEDGEMENTS: We would like to thank Rebecca Adler-Nissen, Jens Blom-Hansen, Gerda Falkner, Morten Kallestrup, Martin Marcussen, Ben Rosamond, Gabriel Pons Rotger, Jarle Trondal and Rikke Wagner as well as our three anonymous reviewers for most constructive comments.

\section{Endnotes}

i A similar work mechanism can also be found in the 'EU pilot' project (COM 2011b) as well as the Tress (social security) and Impel (environment) networks.

${ }^{\text {ii }}$ Before sending out the survey we conducted semi-structured pilot interviews with members of the Danish and British Solvit centres (cf. Couper 2000: 475f).

iii The full survey is available upon request.

iv Solvit survey 2011, Question 4, "How often is your Solvit centre in contact with the European Commission?"

v Solvit survey 2011, Question 7, "Since your Solvit centre was established the amount of contact with the European Commission has in general:". The replies to question 7 also contained one "do not know" and one "missing".

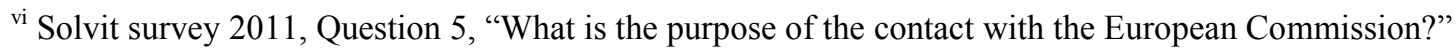

${ }^{\text {vii }}$ Question 15, "To what extent, if at all, do you agree with the following statements about the role of the European Commission in the case handling process?"

viii Solvit Survey 2011, Question 17, "If the European Commission recommends a case solution different from the one preferred by your national public authority, what do you do?"

ix Solvit survey 2011, Question 10, "Of the Solvit cases handled as 'lead' in 2010, what was the outcome?"

${ }^{x}$ We tested the effect and statistical significance of case load relative to a set of other factors (administrative capacity, public support for the EU, adherence to the rule of law, federalism, country voting weight, BNP and Solvit staffing levels) in a panel data analysis. These result confirmed the effect and significance of case load when controlling for other factors, which were not significant. The statistical readouts are available upon request.

\section{References}


Börzel, T. A., Hofmann, T., Panke, D. and Sprungk, C. 2010. “Obstinate and inefficient: Why member states do not comply with European law." Comparative Political Studies 43(11): 13631390.

Chayes, A. \& A. H. Chayes. 1993. “On Compliance.” International Organization, vol. 47(2), 175205.

COM, European Commission 2001. Effective problem solving in the Internal Market ("SOLVIT"). 2001/702. Commission Communication. Published 27.11.2001, Accessed 3.9.2011: http://eurlex.europa.eu/LexUriServ/LexUriServ.do?uri=CELEX:52001DC0702:EN:NOT

COM, European Commission 2007. $24^{\text {th }}$ Annual Report on Monitoring the Application of EU Law: Annex. Published 17.7.2007, Accessed 3.9.2011:

http://ec.europa.eu/eu_law/infringements/pdf/sec_2007_0976_1_en.pdf

COM, European Commission 2011a. Background: Annual reports. Accessed 3.9.2011:

http://ec.europa.eu/solvit/site/background/index_en.htm

COM, European Commission 2011b. $28^{\text {th }}$ Annual report on monitoring the application of EU Law. Published 29 September, Accessed 24.1.2012:

http://ec.europa.eu/eu_law/infringements/infringements_annual_report_28_en.htm

Couper, M. P. 2000. "Web surveys: A review of issues and approaches." Public Opinion Quarterly 64: 464-494.

Egeberg, M. 2008. "European Government(s): Executive Politics in Transition?.” West European Politics, 31(1): 235-257.

Falkner, G., Hartlapp, M., and Treib, O. 2007. "Worlds of compliance: Why leading approaches to European Union implementation are only 'sometimes-true theories'.” European Journal of Political Research 46(3): 395-416. 
Hartlapp, M. 2007. “On Enforcement, Management and Persuasion: Different Logics of Implementation Policy in the EU and the ILO". Journal of Common Market Studies, Vol. 45(3): $653-674$

Haverland, M. and Romeijn, M. 2007. "Do Member States make European policies work? Analysing the EU transposition deficit." Public Administration 85(3): 757-778.

Jensen, C. B. 2007: “Implementing Europe: A Question of Oversight”, European Union Politics, Volume 8 (4), pp. 451-477

Koops, C.E. 2011. "EU Compliance Mechanisms: The Interaction Between the Infringement Procedures, IMS, Solvit and EU Pilot”. Amsterdam Law School Legal Studies Research Paper No. 2011-42.

Maggetti, M. and Gilardi, F. 2011 "The policy-making structure of European regulatory networks and the domestic adoption of standards". Journal of European Public Policy, 18: 6, 830-847.

McCubbins, M. and Schwartz, T. 1984. "Congressional Oversight Overlooked: Police Patrols versus Fire Alarms", American Journal of Political Science, Vol. 28, no. 1, pp. 165-179

Meseguer, C. 2005. "Policy Learning, Policy Diffusion, and the Making of a New Order", The annals of the American Academy of Political and Social Science, Vol. 598, no. 1, pp. 67-82.

Slaughter, Anne-Marie. 2004. A New World Order. Princeton: Princeton University Press

Slaughter, Anne-Marie and Hale, Thomas N. 2010. "Transgovernmental networks and multi-level governance”. In: Henrik Enderlein, Sonja Wälti and Michael Zürn (eds.), Handbook on Multi-level Governance, Cheltenham \& Northampton: Edward Elgar, pp. 358-369

Solvit Survey. 2011. Academic survey of the Solvit network. Own web-survey submitted to and replied by all National Solvit Centers. 
Tallberg, J. 2002. "Paths to Compliance: Enforcement, Management and the European Union.” International Organization, vol. 56(3), 609-643.

Thatcher, M. and Coen, D. 2008. "Network Governance and Multilevel Delegation: European Networks of Regulatory Agencies", Journal of Public Policy, Vol. 28(1): 4971

Thurner, Paul W. and Binder, Martin. 2009. "European Union transgovernmental networks: The emergence of a new political space beyond the nation-state?". European Journal of Political Research 48(1): 80-106

Trondal, J. 2010. An Emergent European Executive Order. Oxford, Oxford University Press.

Versluis, E. 2007. "Even rules, uneven practices: Opening the 'black box' of EU law in action." West European Politics 30(1): 50-67.

WB, Worldbank. 2010. “The Worldwide Governance Indicators: Methodology and Analytical Issues”, Policy Research Working Paper, 5430, Washington: The World Bank

Yesilkagit, K. 2011. "Institutional compliance, European networks of regulation and the bureaucratic autonomy of national regulatory authorities." Journal of European Public Policy 18(7): 962-979. 